\title{
The Relationship between Different Assays for Detection and Quantification of Amyloid Beta 42 in Human Cerebrospinal Fluid
}

\author{
Teresa A. Ellis, ${ }^{1}$ Jinhe Li, ${ }^{1}$ David LeBlond, ${ }^{2}$ and Jeffrey F. Waring ${ }^{1}$ \\ ${ }^{1}$ Neuroscience Biomarkers Group, Abbott Laboratories, Global Pharmaceutical Research and Abbot Park, Development, \\ IL 60064-6123, USA \\ ${ }^{2}$ Exploratory Statistics, Abbott Laboratories, Global Pharmaceutical Research and Abbot Park, Development, \\ IL 60064-6123, USA \\ Correspondence should be addressed to Jeffrey F. Waring, jeff.waring@abbott.com
}

Received 11 January 2012; Accepted 21 February 2012

Academic Editor: Jacob Raber

Copyright ( $) 2012$ Teresa A. Ellis et al. This is an open access article distributed under the Creative Commons Attribution License, which permits unrestricted use, distribution, and reproduction in any medium, provided the original work is properly cited.

\begin{abstract}
Alzheimer's disease (AD), which is characterized by a degeneration of neurons and their synapses, is one of the most common forms of dementia. CSF levels of amyloid $\beta_{42}\left(\mathrm{~A} \beta_{42}\right)$ have been recognized as a strong candidate to serve as an $\mathrm{AD}$ biomarker. There are a number of commercial assays that are routinely employed for measuring $\mathrm{A} \beta_{42}$; however, these assays give diverse ranges for the absolute levels of CSF $\mathrm{A} \beta_{42}$. In order to employ CSF $\mathrm{A} \beta_{42}$ as a biomarker across multiple laboratories, studies need to be performed to understand the relationship between the different platforms. We have analyzed CSF samples from both diseased and nondiseased subjects with two different widely used assay platforms. The results showed that different values for the levels of CSF $\mathrm{A} \beta_{42}$ were reported, depending on the assay used. Nonetheless, both assays clearly demonstrated statistically significant differences in the levels of $\mathrm{A} \beta_{42}$ in CSF from AD relative to age-matched controls (AMC). This paper provides essential data for establishing the relationship between these assays and provides an important step towards the validation of $\mathrm{A} \beta_{42}$ as a biomarker for $\mathrm{AD}$.
\end{abstract}

\section{Introduction}

Alzheimer's disease (AD) is the most common neurodegenerative disorder. Because the disease is often difficult to detect and diagnose at an early stage, a tremendous need exists for the identification and characterization of biomarkers that can be used to diagnose early-stage $\mathrm{AD}$, or for monitoring new therapies for $\mathrm{AD}$ in clinical trials. Much interest has been generated regarding the use of CSF $\mathrm{A} \beta_{42}$ as a biomarker for diagnosing and tracking $\mathrm{AD}$ progression $[1,2]$. Several different commercially available assays for measuring $A \beta_{42}$ are currently employed across laboratories. These assays give diverse values for the levels of CSF A $\beta_{42}[3,4]$. The relationships between the reported CSF $A \beta_{42}$ values from these different assays are unclear, but researchers agree in the importance of standardizing assays for CSF A $\beta_{42}$ [4].

Schoonenboom et al. compared the A $\beta_{42}$ CSF measurements from two widely used $\mathrm{A} \beta_{42}$ ELISA assays using the same CSF sample. Our data extends their findings by directly comparing human CSF samples from both diseased and non diseased subjects with two different widely-used assay platforms, one of which uses colorimetric detection, while the other employs electrochemiluminescence (ECL) detection. Comparisons were made to determine if the assays gave similar values and were able to distinguish CSF from Alzheimer's subjects or age-matched controls based.

\section{Materials and Methods}

2.1. Subjects. Human cerebrospinal fluid (CSF) samples were purchased from Precision Med, Inc. (San Diego, CA), which is in compliance with all applicable rules and regulations for human sample collection and dissemination. CSF samples from 23 individuals with $\mathrm{AD}$ (14 males, 9 females, average age 78 , average MMSE score 17) and 22 age-matched controls (11 males, 11 females, average age 77) were tested. To avoid any effects from multiple freeze-thaw cycles, $60 \mu \mathrm{L}$ aliquots of each CSF sample were placed in randomly assigned wells in a lo-bind polypropylene tray (Micronic North America, McMurray, PA). CSF was stored at $-80^{\circ} \mathrm{C}$ until analysis. 


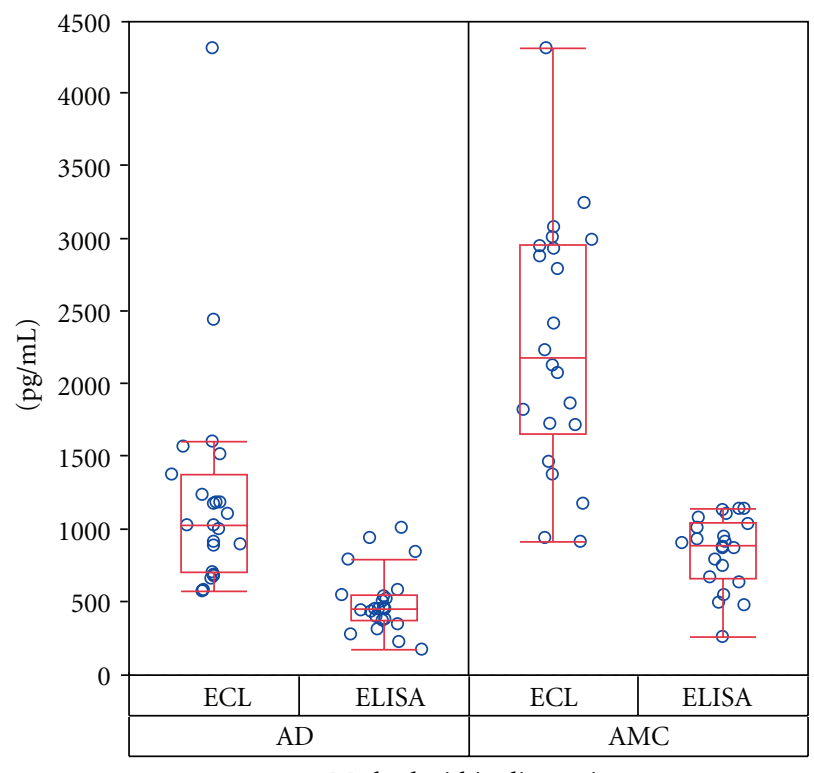

(a)

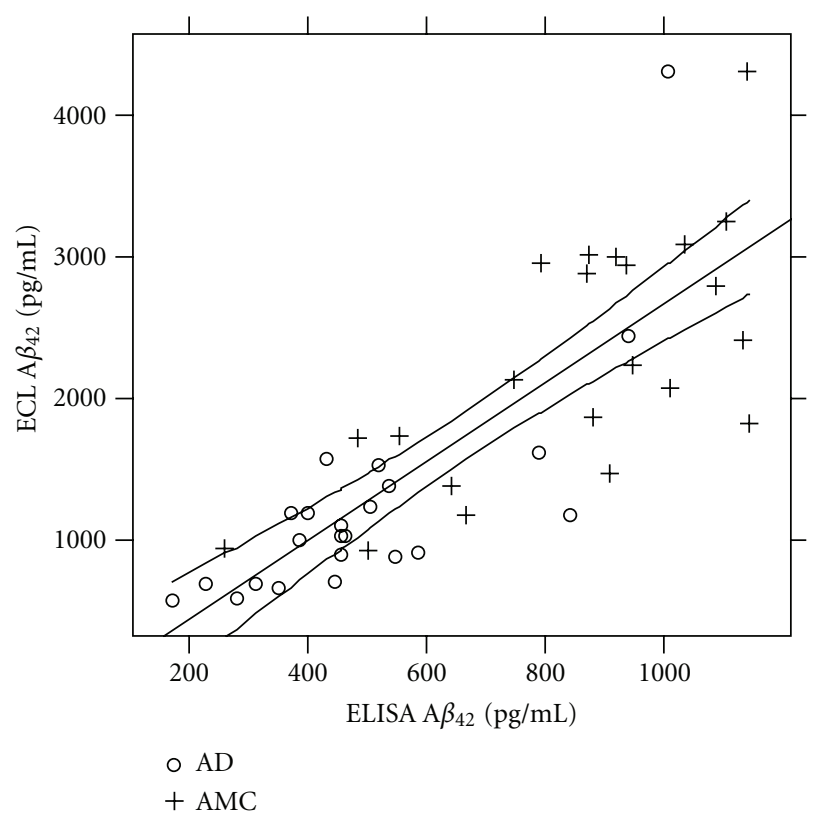

(b)

FIgure 1: (a) CSF A $\beta_{42}$ levels measured in both ELISA and ECL assay. Box plots of CSF A $\beta_{42}$ levels from ELISA and ECL separated by diagnosis (AD and AMC) and method of detection. Boxes represent the interquartile ranges: bottom of box, black dot, and top of box indicate the 25,50, and 75th percentile of the data. The whiskers (dashed bars) extend to the most extreme data points, which are no more than 1.5 times the height of the box away from the top or bottom of the box. (b) Correlation between ELISA and ECL. Correlation coefficients $r=0.819$.

All samples were assayed in duplicate in both $\mathrm{A} \beta_{42}$ assays, conducted by the same experienced scientist.

2.2. CSF Analysis. Innotest $\beta$-Amyloid ${ }_{1-42}$ (Innogenetics, Alpharetta, GA) is a solid-phase ELISA for measuring the levels in human CSF utilizing colorimetric detection with peroxidase-labeled streptavidin. The ELISA was performed as outlined by the manufacturer's instructions. Absorbance at $450 \mathrm{~nm}$ was measured on the SpectraMax M2 (Molecular Devices, Sunnyvale, CA), and analysis was preformed using Softmax 5.2 software. The limit of detection (LOD) of $50 \mathrm{pg} / \mathrm{mL}$ was calculated by the manufacture as the mean of 8 determinations of the sample diluent.

MSD 96-well MULTI-ARRAY Human (6E10) A $\beta_{x-42}$ assay (MesoScale Discovery, Gaithersburg, MD) was preformed as outlined by the manufacturer's instructions. Analysis was performed using MSD workbench version 3.0.17.3 (MSD, Gaithersburg, MD). An LOD of approximately $20 \mathrm{pg} / \mathrm{mL}$ was calculated by the manufacture based on data obtained from 4 different product lots (Table 1). All calibrators were prepared in siliconized polypropylene tubes (Sigma-Aldrich, St. Louis, MO), and CSF samples were diluted in 96-well u-bottom polypropylene plates (Costar, Lowell, MA).

2.3. Statistical Analysis. All statistical analyses and graphics were performed using either SAS JMP version 8 or R version 2.9.0. A $P$ value $<0.05$ was taken to indicate statistical significance. Statistical testing for differences in mean $A \beta_{42}$
TABLe 1

\begin{tabular}{lccc}
\hline & $\begin{array}{c}\text { ELISA } \\
\mathrm{pg} / \mathrm{mL}\end{array}$ & $\begin{array}{c}\text { EC } \\
\mathrm{pg} / \mathrm{mL}\end{array}$ & $\begin{array}{c}\text { Ratio } \\
\text { ECL/ELISA }\end{array}$ \\
\hline $\mathrm{AD}(n=23)$ & $500.4 \pm 44.6$ & $1235.8 \pm 165.7$ & 2.5 \\
Mean $\pm \mathrm{SE}$ & & & \\
$\mathrm{AMC}(n=22)$ & $848.3 \pm 51.9$ & $2280.5 \pm 184.6$ & 2.7 \\
Mean $\pm \mathrm{SE}$ & $50 \mathrm{pg} / \mathrm{mL}$ & $10-20 \mathrm{pg} / \mathrm{mL}$ & \\
LOD & & & 2.6 \\
\hline Average & &
\end{tabular}

level among the two diagnosis groups (AD and $\mathrm{AMC}$ ) was made using a two-sided, two-sample $t$-test.

\section{Results}

The $\mathrm{A} \beta_{1-42}$ ELISA standard curve showed a dynamic range of 125 to $2000 \mathrm{pg} / \mathrm{mL}$, with an LOD of $50 \mathrm{pg} / \mathrm{mL}$, and the average CV based on sample duplicates was 3.9\%. The $\mathrm{A} \beta_{x-42}$ ECL assay standard curve showed a dynamic range of 12 to $3000 \mathrm{pg} / \mathrm{mL}$, with an LOD of approximately $20 \mathrm{pg} / \mathrm{mL}$, and the average CV based on sample duplicates was $7.1 \%$ (data not shown). The $\mathrm{A} \beta_{42}$ levels in the $45 \mathrm{CSF}$ samples determined by ELISA and ECL assay are shown in Figure 1(a). The $\mathrm{A} \beta_{42}$ levels of all the CSF samples were above LODs in both assays. The means of $\mathrm{A} \beta_{1-42}$ measured by ELISA were significantly lower in $\mathrm{AD}$ patients compared with AMC (500.4 versus $848.3 \mathrm{pg} / \mathrm{mL}$, resp.), $\left(P<0.0001^{*}\right)$. The average $\mathrm{CV}$ based on sample duplicates was $6 \%$. Mean $\mathrm{A} \beta_{x-42}$ 
measured by ECL assay were also significantly lower in $\mathrm{AD}$ patients compared with AMC (1235.8 versus $2280.5 \mathrm{pg} / \mathrm{mL}$, resp.) $\left(P<0.0001^{*}\right)$. The average $\mathrm{CV}$ based on sample duplicates was $8.4 \%$. Although absolute concentrations varied between the ELISA and ECL, the correlation coefficient for CSF A $\beta_{42}$ was $r=0.819$ and highly significant $(P<0.0001)$ (Figure 1(b)).

\section{Discussion}

We provide here a direct comparison between two commonly used assays, ELISA and ECL assay, in measuring $\mathrm{A} \beta_{42}$ levels in human CSF. Both the ELISA and ECL assay showed that $\mathrm{A} \beta_{42}$ was higher in the AMC than the AD group. These observations in subject differentiation are similar to other published reports [1, 4-6].

We observed that in general $\mathrm{A} \beta_{42}$ levels were 2.6-fold higher in the ECL assay relative to the ELISA. The observed differences may be related to a number of factors including the matrix (i.e., different assay dilution buffers and reagents), the purity of the calibrators, and differences in the affinity of the capture and detection antibodies $[3,7]$. The ELISA assay uses monoclonal antibody $21 \mathrm{~F} 12$ as the capture antibody, which recognizes $A \beta_{1-42}$. In contrast, ECL assay uses an undisclosed antibody, which recognizes $\mathrm{A} \beta_{x-42}$ as the capture antibody. There is also a lack of synchronization between the two assays due to the difference between the two calibrators. We conducted an experiment swapping the calibrators between the two kits. Both assays detected the other kits' calibrator; however, the \% recovery was not at an acceptable level (data not shown).

Although both are plate-based methods, the detection technologies for measuring the $\operatorname{CSF} A \beta_{42}$ concentrations are different and could be a contributing factor to the underlying difference. The ELISA signal is detected with a peroxidase-labeled streptavidin antibody and the result is colorimetric, which provides the desired sensitivity but less dynamic range. The ECL signal is detected by incorporating a SULFOTAG labeled antibody that emits light upon electrochemical stimulation initiated at the electrode, which provides sensitivity similar to the ELISA but a broader dynamic range.

\section{Conclusion}

Currently, quality control efforts are under investigation to evaluate interlaboratory variance components and to aid in the standardization of CSF $A \beta_{42}$ measurements [1]. In addition, larger harmonization studies are needed that include the assays studied here as well as other manufactures assays for the measurement of $A \beta_{42}$ in human CSF. The present study provides an important first step by comparing and establishing the relationship between two widely used platforms for measuring $\mathrm{A} \beta_{42}$.

\section{References}

[1] K. Blennow, E. Vanmechelen, and H. Hampel, "CSF total tau, $A \beta_{42}$ and phosphorylated tau protein as biomarkers for Alzheimer's disease," Molecular Neurobiology, vol. 24, no. 1-3, pp. 87-97, 2001.
[2] C. Mulder, N. A. Verwey, W. M. Van Der Flier et al., "Amyloid$\beta(1-42)$, total tau, and phosphorylated tau as cerebrospinal fluid biomarkers for the diagnosis of Alzheimer disease," Clinical Chemistry, vol. 56, no. 2, pp. 248-253, 2010.

[3] M. Bjerke, E. Portelius, L. Minthon et al., "Confounding factors influencing amyloid $\beta$ concentration in cerebrospinal fluid," International Journal of Alzheimer's Disease, vol. 2010, Article ID 986310, 11 pages, 2010.

[4] N. S. M. Schoonenboom, C. Mulder, H. Vanderstichele et al., "Differences and similarities between two frequently used assays for amyloid $\beta_{42}$ in cerebrospinal fluid," Clinical Chemistry, vol. 51, no. 6, pp. 1057-1060, 2005.

[5] N. Mattsson, H. Zetterberg, O. Hansson et al., "CSF biomarkers and incipient Alzheimer disease in patients with mild cognitive impairment," Journal of the American Medical Association, vol. 302, no. 4, pp. 385-393, 2009.

[6] T. Sunderland, G. Linker, N. Mirza et al., "Decreased $\beta$-Amyloid1-42 and Increased Tau Levels in Cerebrospinal Fluid of Patients with Alzheimer Disease," Journal of the American Medical Association, vol. 289, no. 16, pp. 2094-2103, 2003.

[7] T. S. M. Reijn, M. O. Rikkert, W. J. A. Van Geel, D. de Jong, and M. M. Verbeek, "Diagnostic accuracy of ELISA and xMAP technology for analysis of amyloid $\beta 42$ and tau proteins," Clinical Chemistry, vol. 53, no. 5, pp. 859-865, 2007. 


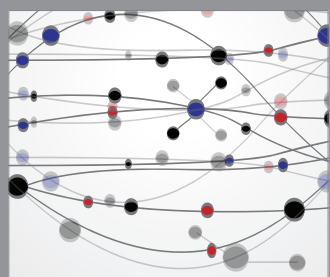

The Scientific World Journal
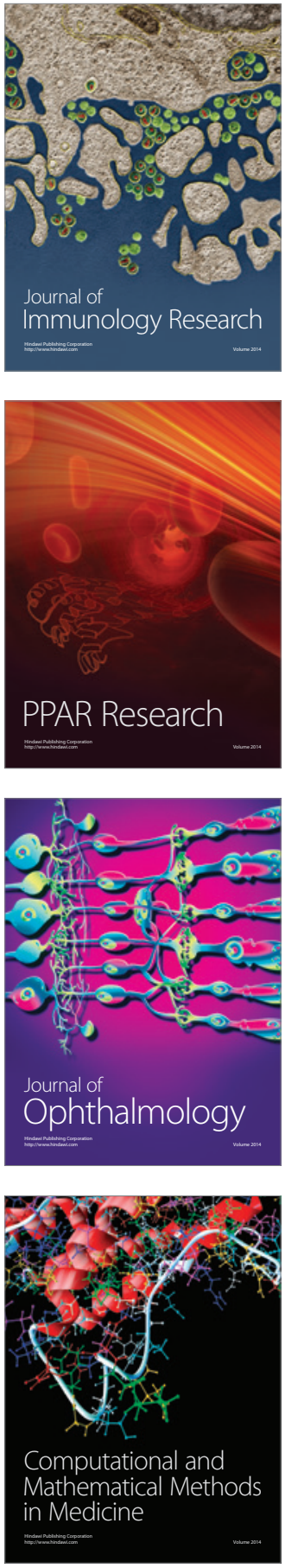

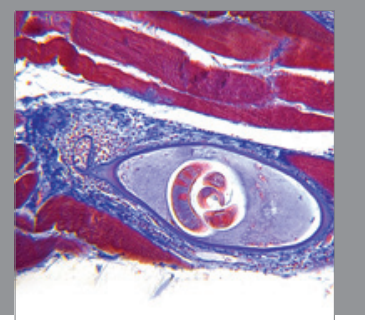

Gastroenterology

Research and Practice
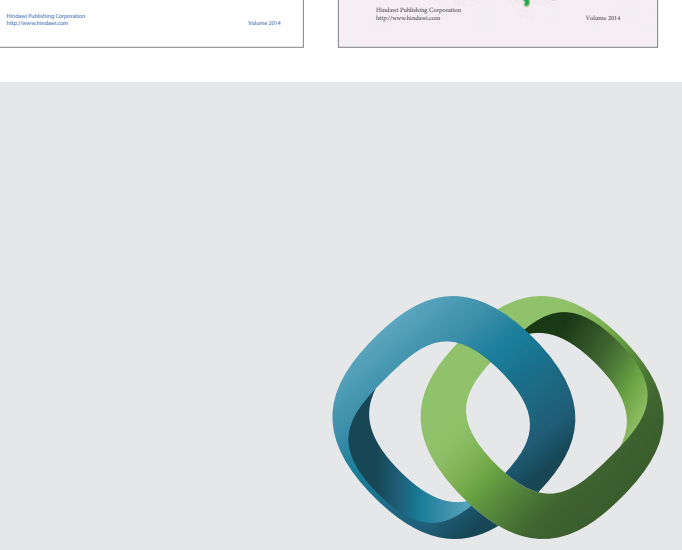

\section{Hindawi}

Submit your manuscripts at

http://www.hindawi.com
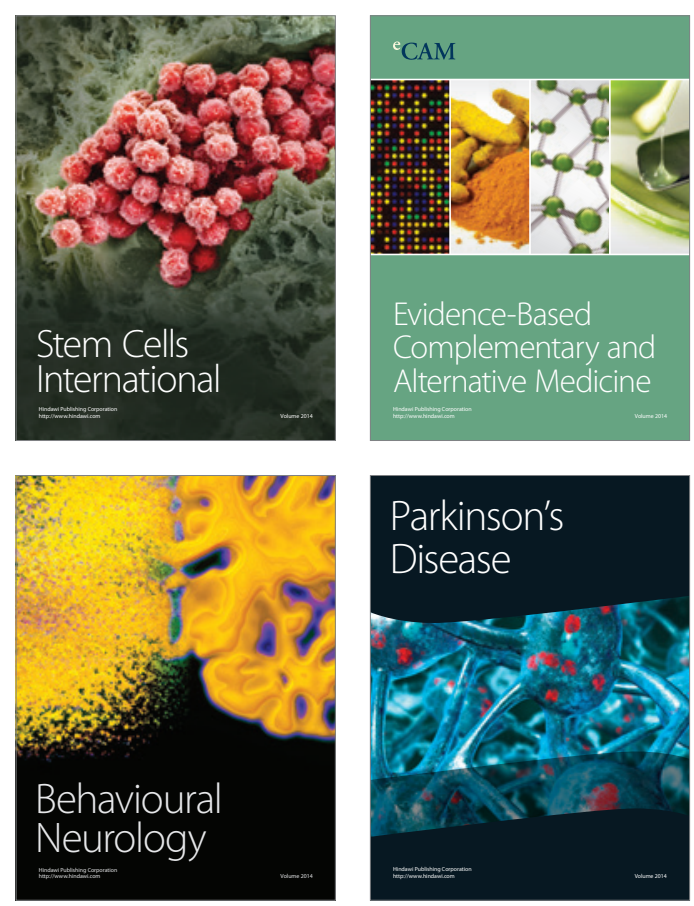

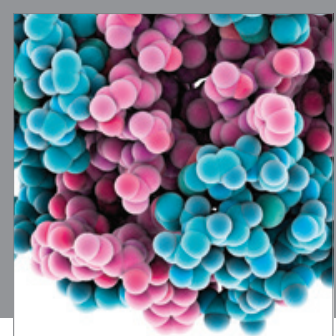

Journal of
Diabetes Research

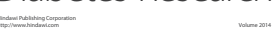

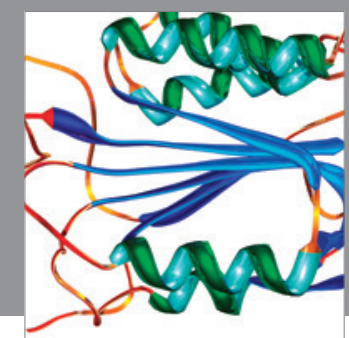

Disease Markers
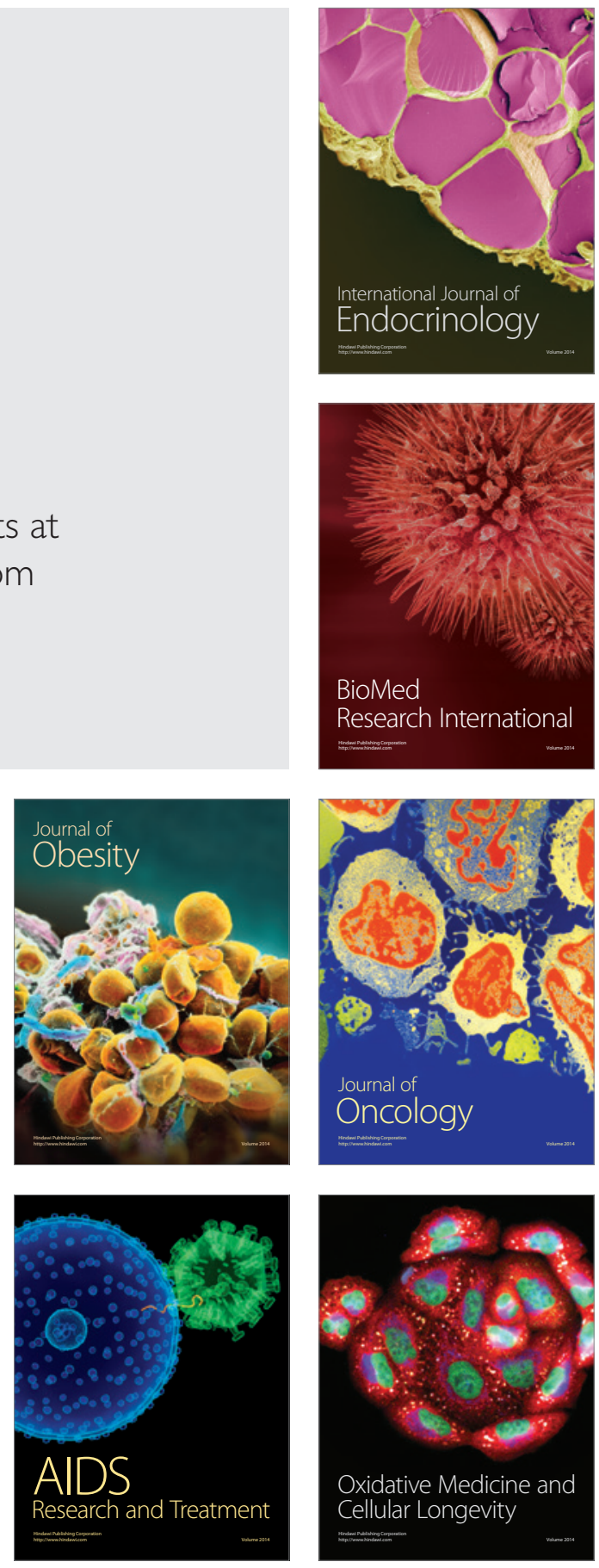